\title{
Influence of mixing methods on the properties of high density polyethylene nanocomposites with different carbon nanoparticles
}

\author{
Ricardo Fischer Brandenburg ${ }^{1}$, Carlos Mauricio Lepienski ${ }^{2}$, \\ Daniela Becker ${ }^{1}$, Luiz Antonio Ferreira Coelho ${ }^{1}$
}

\footnotetext{
${ }^{1}$ State University of Santa Catarina -UDESC

${ }^{2}$ Federal University of Parana - UFPR

e-mail:coelholaf@gmail.com
}

\begin{abstract}
In this paper, nanocomposites with multiwalled carbon nanotubes (MWCNT) or graphene nanosheets were prepared using a high density polyethylene (HDPE) matrix. Two different processes were employed: a solution method and a melt mixing method. The crystallinity index of the HDPE showed similar levels in nanocomposites after the addition of carbon nanotubes. It can be seen that the preparation process modified the degree of crystallinity of the HDPE matrix with graphene nanosheets. Nanocomposites prepared by the solution method showed a decrease in the crystallinity index. The addition of carbon nanotubes led to an increase of Young's Modulus with an increase in the MWCNT quantity, regardless of the preparation process used, with a $22.8 \%$ increase for composites with $0.5 \mathrm{wt} \%$ of CNTs. The nanocomposites with graphene nanosheets exhibited a different behavior with each mixing method. Nanocomposites prepared by the solution method showed a higher Young's Modulus than those prepared by melt mixing. Results of transmission electronic microscopy and field emission scanning electronic microscopy indicated homogeneous dispersion for carbon nanotubes in melt mixing. Graphene nanocomposites showed some agglomerates, with smaller platelets in the nanocomposites prepared by solution mixing compared to that prepared by the melt mixing.
\end{abstract}

Keywords: nanocomposites, high density polyethylene, graphene, carbon nanotube, mixing methods

\section{INTRODUCTION}

Traditional polymer composites use a dispersed phase with size on the order of micrometers. A classic example is carbon fiber and glass fiber, and the percentage added in the composites sometimes can exceed the order of $40 \% \mathrm{v} / \mathrm{v}$ [1]. The composites may exhibit regions with internal stresses and this may lead to weakness of the composite structure and the final properties provided by composites are lower than the theoretical calculations. Classical composites, in general, are not multifunctional. Nanocomposites emerged in the late 1980s, and showed significant changes in polymer properties [2]. The nanocomposites exhibit a dispersed phase with one or more dimensions smaller than 100nm, and are characterized by possessing high surface areas, allowing the modification of properties with lower volume fraction in the dispersed phase, compared to a traditional composite [1]. Particles in the nanosize range have large surface areas per volume, generally around 1000 times larger than in traditional composites. The surface area and aspect ratio of nanoparticles are crucial in the stress transfer from the dispersed phase to the matrix. Once dispersed in a homogeneous manner, they can generate a region called interphase without a region of internal stress and very often nanocomposites are multifunctional. Once obtained the state of interphase percolation, the whole polymer matrix will be modified, and therefore it is a material with maximum performance in the use of nanoparticles [3].

There are several ways for dispersing nanofillers in polymer matrices, including in situ polymerization and melting or solution mixing. The melt mixing consists of dispersing the nanoparticles by mechanical shearing action in the polymer matrix in the molten state. This method offers greater facility of preparation because it is based on the traditional methods of polymer processing. The solution mixing promotes the dispersion of nanoparticles in a solution containing the solubilized polymer matrix. Due to its low viscosity, the method tends to facilitate the dispersion of nanoparticles in the polymer matrix, which may or may not be associated with high energy sonication devices, and mechanical agitation to promote exfoliation/dispersion of nanoparticles and assist in achieving a state of homogeneous dispersion. This method has been very efficient 
in dispersing nanoparticles, but in general, large quantities of solvent compared to the mass of the nanocomposite obtained are required $[4,5]$. In addition, from the best of our knowledgement, there are a few works that had prepared nanocomposites using solution mixing techniques [6-10] with HDPE as a matrix, very probably due to time consumption of the method and the fact that organic solvents in general are employed. In our previous work [11], we observed significant differences in the nanocomposites morphology and consequently in mechanical and thermal properties using different mixing techniques.

Carbon nanotubes are tubular structures of carbon atoms, and have a high Young's modulus, flexibility, low density, excellent thermal and electric conductivity and a high aspect ratio [12]. Mittal [5] mentioned several studies using carbon nanotubes in modifying properties of different polymeric matrixes, with increased Young's modulus, thermal and electrical conductivity. Graphenes are plane and two-dimensional structures formed by carbon atoms having only one atom thick [13] and it is found in agglomerates containing in general a different number of packed sheets, known as platelets. They have excellent dimensional stability, thermal and electrical conductivity, flexibility and exceptional mechanical strength [8].

Several studies using carbon nanotubes (CNT) and graphene in polyethylene using different preparation methods are found in the literature, but few compare the different methods and these two nanoparticles. Jeon et al. [9] studied polyethylene and single-wall carbon nanotube (SWCNT) nanocomposites made by solution dispersion, and observed a homogeneous dispersion at concentrations up to $8 \mathrm{wt} \%$ of SWCNT and percolation thresholds for concentrations up to $0.13 \mathrm{wt} \%$. They did not observe change in the crystallization temperature. Chrissafis et al [14], obtained nanocomposites with different particles through melt mixing using a torque rheometer. In nanocomposites containing $2.5 \mathrm{wt} \%$ of carbon nanotubes, no homogeneous dispersion of carbon nanotubes throughout the matrix was observed. The DSC results showed no change in the melt temperature and they observed an increase of $30 \%$ in the Young's modulus in nanocomposites. Valentino et al [15] studied the dispersion of different concentrations of carbon nanotubes in HDPE by means of a torque rheometer. The results obtained by them indicate a homogeneous dispersion of CNTs in HDPE, indicating a percolation threshold for contents between $1 \mathrm{wt} \%$ and $2.5 \mathrm{wt} \%$. He et al [8] prepare HDPE and carbon nanotube nancomposites by solution intercalation and observed a decrease in the HDPE crystallinity degree and an increase in half-crystallization time, implying the presence of MWNTs can give rise to a decreased rate of crystallization. They related this behavior with high superficial area of CNT so that probably restrict molecular motion of PE and consequently interfere with crystal growth. They could act as the nucleating agent to facilitate the crystallization of PE in the hybrids while confine the crystallization of PE. Jiang and Drzal [16] showed an increase in the crystallinity degree and in the melt temperature in nanocomposites with graphene obtained by melt intercalation. The authors related this behavior with the possibility of the graphenes act as nucleated agent. They also reported that the crystallinity degree is increased up to a certain graphene concentration, a small platelet distance could reduce the potential for polymer crystallization.

El Achaby and Qaiss [17] prepared nanocomposites with carbon nanotubes and graphene in a high density polyethylene matrix using a torque rheometer. The results pointed out changes in the mechanical properties using 3\%wt of graphene. They observed an increase of $87 \%$ in the Young's modulus. Also, they reported an increase of 57\% in Young's modulus with the same mass fraction of carbon nanotubes (3\%). The authors associated behavior of the graphene nanocomposites with the greater particle surface area and high aspect ratio of the 2-D surface, thus increasing interaction with the polymer chains due to a high interphase area. Using solution mixing, Du et al [18], obtained nanocomposites with graphene or with carbon nanotubes. They observed an electrical percolation threshold at $0.32 \mathrm{wt} \%$ of carbon nanotubes and at $1.0 \mathrm{wt} \%$ of graphene. A three-dimensional conduction network in the nanocomposites with carbon nanotubes is cited in the article as being responsible for the electrical performance compared to a $2 \mathrm{D}$ conduction system shown by graphene. They associate this behavior to the difficulty of graphene exfoliation, and consequently inadequate distribution occurs due to the large surface area, showing great interparticle interaction originated by van der Waals forces.

In this scenario, it was decided to use two different techniques for preparing HDPE nanocomposites, a very common which is melting mixing and an unusual that is solution mixing. Therefore, the aim of this study is to evaluate the influence of different dispersion methods and different contents of carbon nanotubes or graphenes on the morphology, on the thermal and on the mechanical properties of nanocomposites of HDPE. 


\section{MATERIALS AND METHODS}

\subsection{Materials}

The resin used in this work was HDPE (HC760LS-L), supplied by Braskem $(\mathrm{Mn}=23,000 \mathrm{~g} / \mathrm{mol}$ and MW= $68,500 \mathrm{~g} / \mathrm{mol}$ ). MWCNTs were supplied by Shengdu Organic Chemicals, commercially denominated as TNIM4, with purity higher than $85 \%$, electrical conductivity of $100 \mathrm{~S} / \mathrm{cm}$, diameters ranging from 10-30 nm and lengths from 10-30 $\mu \mathrm{m}$. Graphene was supplied by Angstron Materials (nanosheet with 50 to $100 \mathrm{~nm}$ of thickness and average length was less than $5 \mu \mathrm{m}$ ) with purity higher than $98 \%$. All experiments were performed using 0.5 or $1.0 \mathrm{wt} \%$ of carbon nanoparticles relative to the mass of HDPE, except the neat system. The nanocomposite samples prepared in this study were obtained by solution or melt mixing. The adopted nomenclature for this study is presented in Table 1.

Table 1: Nomenclature and composition of the samples.

\begin{tabular}{|c|c|c|c|}
\hline Method & $\begin{array}{l}\text { Nanoparticle } \\
\text { (NPT) }\end{array}$ & Sample & $\%$ of NPT \\
\hline \multirow{5}{*}{ 节 } & - & P00S & 0.0 \\
\hline & MWCNT & N05S & 0.5 \\
\hline & MWCNT & N10S & 1.0 \\
\hline & graphene & G05S & 0.5 \\
\hline & graphene & G10S & 1.0 \\
\hline \multirow{5}{*}{$\begin{array}{l}\stackrel{\infty}{\Xi} \\
\stackrel{\Xi}{\Xi} \\
\Xi\end{array}$} & - & $\mathrm{P} 00 \mathrm{M}$ & 0.0 \\
\hline & MWCNT & N05M & 0.5 \\
\hline & MWCNT & N10M & 1.0 \\
\hline & graphene & G05M & 0.5 \\
\hline & graphene & G10M & 1.0 \\
\hline
\end{tabular}

\subsection{Sample preparation}

The $10 \mathrm{~g}$ of polyethylene was dissolved in $1000 \mathrm{~mL}$ of 1,2 dichlorobenzene. The solution was maintained at $130^{\circ} \mathrm{C}$ and stirred until complete polymer dissolution. The appropriate volume of nanoparticles was added in another flask with $80 \mathrm{~mL}$ of 1,2 diclorobenzene. This mixture was previously manually stirred, followed by sonication for 30 minutes at $150 \mathrm{~W}$, using a Sonics VCX 750 sonicator device with a tip at $130^{\circ} \mathrm{C}$. Before the sonication, the solution with nanoparticles was added into the polymer solution and the magnetic stirrer was used for mixing the components for ten minutes. Methanol was used as a non-solvent to separate the nanocomposite. The precipitation was done at $6^{\circ} \mathrm{C}$ and maintained for $8 \mathrm{~h}$. The nanocomposite was filtered and dried under vacuum at $60^{\circ} \mathrm{C}$ for 48 hours. The melt mixing process was performed in a Hake torque rheometer with a $50 \mathrm{~cm}^{3}$ mixing chamber and standard rotors, operated at $180^{\circ} \mathrm{C}$ and $50 \mathrm{rpm}$ for 10 minutes. The nanocomposites were compressed and molded into a disk of $2 \mathrm{~mm}$ thickness and $50 \mathrm{~mm}$ diameter using a hydraulic press at $180^{\circ} \mathrm{C}$ for $5 \mathrm{~min}$ by applying a force of $5 \mathrm{~T}$ and cooled with water to room temperature.

\subsection{Characterization techniques}

The melting and crystallization temperature and crystallinity degree were obtained by differential scanning calorimetry (DSC), in a NETZSCH DSC $200 \mathrm{~F} 3$ device, with a heating rate of $10{ }^{\circ} \mathrm{C} / \mathrm{min}$, from $30^{\circ} \mathrm{C}$ to 300 ${ }^{\circ} \mathrm{C}$ (under nitrogen atmosphere). The percent of crystallinity (Xc) was determined from the enthalpy of crystallization of HDPE, Equation 1, using a value of $\Delta \mathrm{H}=293 \mathrm{~J} / \mathrm{g}$ for HDPE $100 \%$ [19] crystalline and the enthalpy values were corrected for HDPE weight present in the nanocomposite.

$$
X_{c}=\left(\frac{\Delta H_{\text {amostra }}^{o}}{\Delta H_{f}^{0}}\right) x 100
$$

The weight loss was obtained by thermogravimetric analysis (TGA), in a Shimadzu TGA-50 device with a heating rate of $20^{\circ} \mathrm{C} / \mathrm{min}$ from $30^{\circ} \mathrm{C}$ to $500^{\circ} \mathrm{C}$ (under nitrogen atmosphere). 
The nanoindentation was performed on a Nanoindenter XP device using a Berkovich indenter. By applying the method of Oliver and Pharr [20], measurements of elastic modulus and nanohardness were done through sixteen indentations arranged in a 4x4 indentation matrix. Each indentation was spaced $200 \mu \mathrm{m}$ from the previous. A maximum load of $50 \mathrm{mN}$ was used, with 8 cycles of loading and unloading in each indentation.

Ultrathin sections of $30 \mathrm{~nm}$ were cut from the compression molded disks with a diamond knife at $85^{\circ} \mathrm{C}$, using an RCM Power Tome X Ultramicrotome. Sections were collected on the surface of a waterdimethylsulfoxide $(60 / 40 \mathrm{v} / \mathrm{v})$ bath cooled at $-60^{\circ} \mathrm{C}$. A JEOL JEM-2100 transmission electron microscope was used for the images. The morphology was also analyzed by field emission electronic microscopy (FEG). The images were obtained by a Jeol JSM 6701F FEG and samples were fractured under liquid nitrogen.

\section{RESULTS AND DISCUSSION}

The images obtained by FEG with $0.5 \mathrm{wt} \%$ of nanoparticles are shown in Figure 1 . It is well known from that the dispersion state can change the mechanisms of fracture toughness in nanocomposites. More agglomerates may allow the appearance of crack deflection for instance. Although, any change can be seen in the fracture morphology regardless of the dispersion method for MWCNT nanocomposite. The dispersion methods altered the fracture morphology for nanocomposites with graphene. In the samples prepared by the solution mixing process G05S (Figure 1 (c)), the plastic deformation is less evident than that prepared by the melt mixing process G05M (Figure 1 (d)). It can be seen in figure 1d signs of too many coarse fibrillation structures which is not present in figure 1c. These fibrillation are signs of crazing in the material and this is a strong evidence of plastic deformation. El Achaby \& Quais [17] also observed less plastic deformation in nanocomposites with graphene than in those with carbon nanotubes. This behavior can be related with graphene dispersion state in the polymeric matrix. In Figure 2, it is possible to observe the decrease of graphene nanosheet size in the nanocomposites prepared by the solution method (Fig 2(b)). In Figure 2, it is possible to observe the decrease of graphene nanosheet size in the nanocomposites prepared by the solution method (Fig 2(b)).The diffusion coefficient of a nanoparticle is smaller in a media with solvent/amorphous polymer than in a media of an amorphous polymer. Stokes-Einstein equation in fact predicted this behavior in fair agreement with several studies. In our case, it was used solvent in the solution method which decreased the viscosity of the media given a higher diffusion coefficient to the nanoparticle. In this way, it is more probable to find smaller graphene nanoplateletes in this method than in melt dispersion since the viscosity of the neat polymer is much higher than the solution of solvent/polymer. 


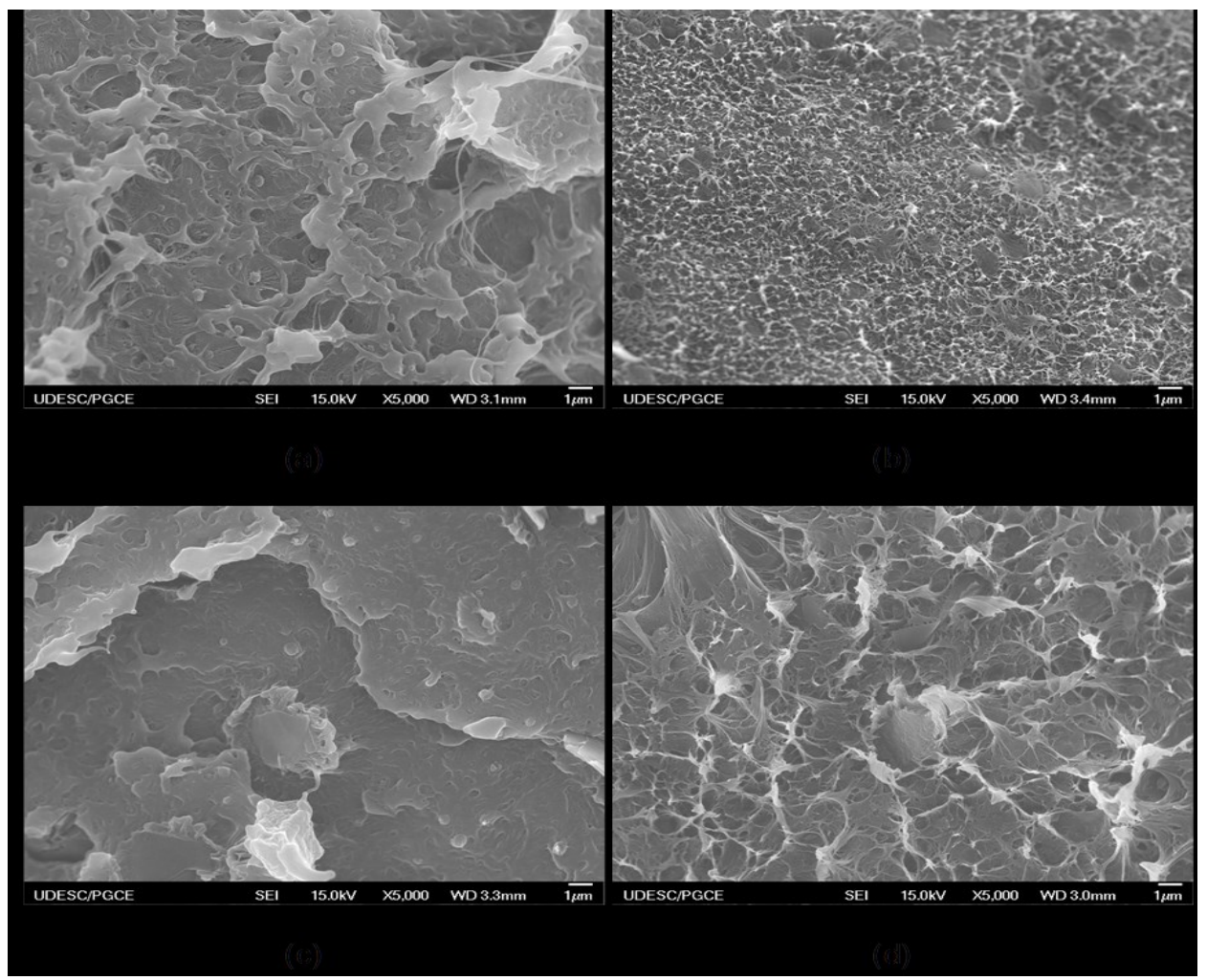

Figure 1: FEG micrographs of (a)N05S, (b) N05F, (c) G05S, (d) G05F nanocomposites.

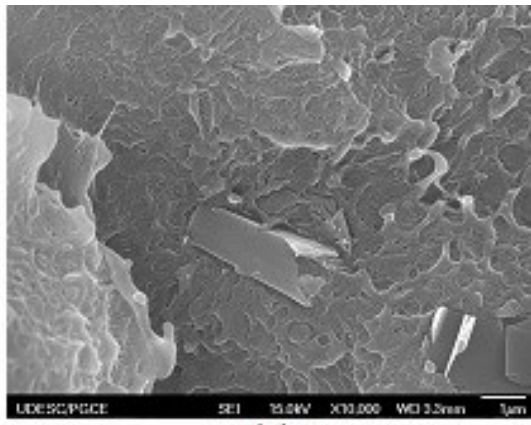

(a)

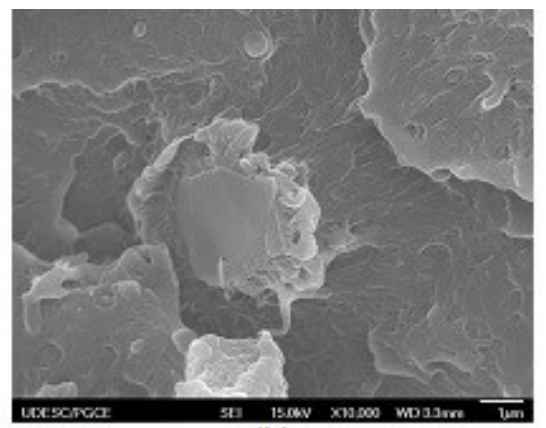

(b)

Figure 2: FEG micrographs (a) Graphene nanosheets in HDPE obtained by melt dispersion (G10F); (b) Graphene nanosheets in HDPE obtained by solution (G05S)

Figure 3 presents transmission electronic microscopy images of nanocomposites with $0.5 \mathrm{wt} \%$ of carbon nanotubes or $0.5 \mathrm{wt} \%$ graphene. It is possible to observe carbon nanotubes agglomerates in N05S (Figure 3(b)). These agglomerates are well distributed in the sample. They had a morphology with good distribution but poor dispersion [2]. In the nanocomposites obtained by the melt process (Figure 3(a)), we see a better dispersion of carbon nanotubes than the samples obtained by the solution mixing process. This behavior can be related to the fact that in the solution mixing process, the mixture was maintained for 10 minutes of simple mechanical stirring after sonication of the nanoparticles in the solvent. This could be sufficient to promote reagglomeration of carbon nanotubes before extraction of the solution with the use of methanol. The addition of graphene nanosheets has a different behavior. The samples obtained by the solution process show smaller agglomerates of graphene than those obtained by melt mixing. This behavior can be related to high energy sonification used in the solution mixing process. 


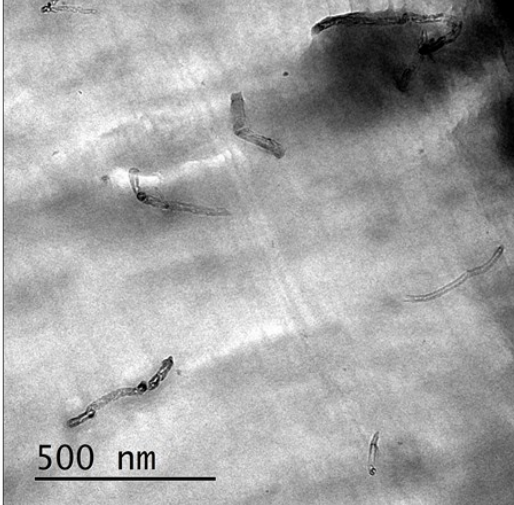

(a)

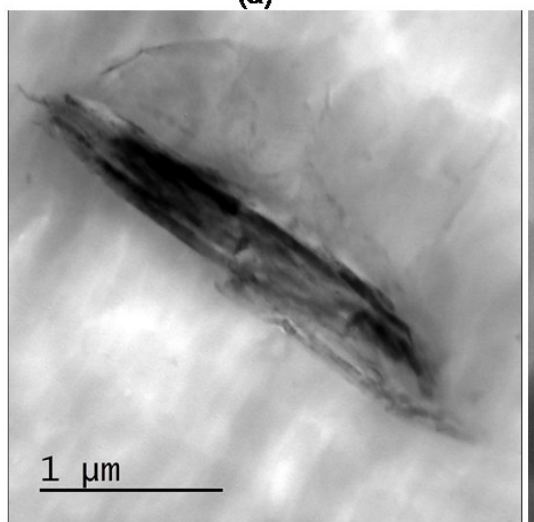

(c)

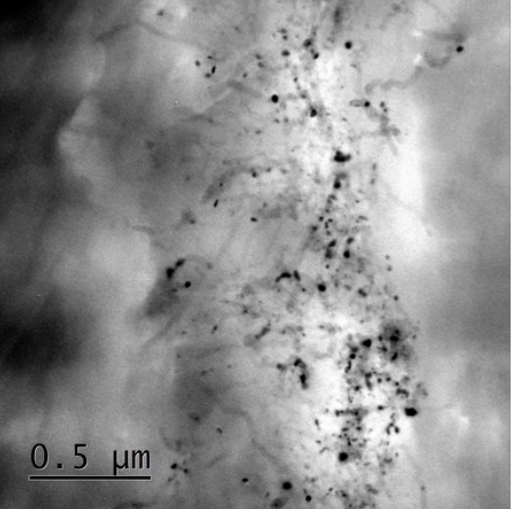

(b)

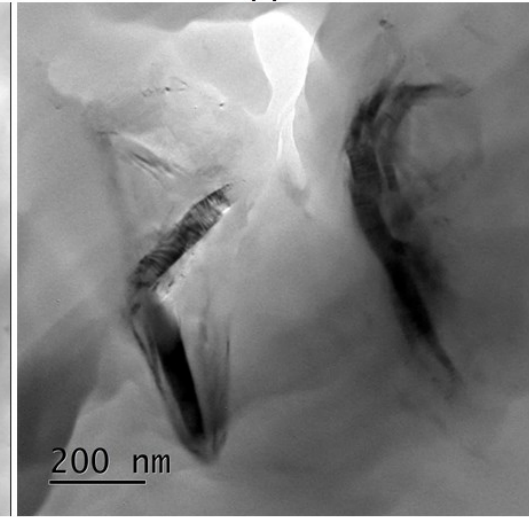

(d)

Figure 3 - TEM micrographs of N05M (a), N05S (b), G05M (c) and G05S (d) nanocomposites.

Table 2 shows melt and crystallization temperature and crystallinity index obtained by DSC and Figure 4 present the DSC thermograms. It can be observed that melt and crystallization temperature showed no significant change regardless of the nanoparticle and the preparation process. This behavior was also observed by different authors [14, 21-23]. The preparation methods interfere in the crystallinity index of neat HDPE (P00S and P00M). The crystallinity index of neat HDPE prepared by solution (PE00S) is 7\% higher than that obtained by melting mixing. This behavior can be related with the cooling rate. The critical demixing temperature was located far below the melting curve, the resulting crystal morphology is a single, lamellar crystallite grows from the homogeneous solution [24]. For melting process highly oriented cylindrites or anisometric spherulites compressed in the strain direction and having their primary nuclei more or less aligned in rows parallel to the strain is formed [25]. These differences in morphology could altered the crystallizantion degree.

The addition of MWCNT did not significantly alter the crystallinity degree in the nanocomposites obtained by solution melting. For the melting process, it is possible to observe an increase of $13 \%$ for nanocomposites containing $0.5 \mathrm{wt} \%$ carbon nanotube and $9 \%$ for nancomposites containing $1.0 \mathrm{wt} \%$. In the literature, we see decreases in the crystallinity degree for high concentration of carbon nanotubes in the nanocomposites $[8,22]$ The influence of preparation methods can be attributed to the dispersion of carbon nanotube as seen in Figure 3(a) and (b). He et al [8] affirmed that the inorganic component could act as a nucleating agent for crystallization or the inorganic network could confine the crystallization restricting the polymer movement and decrease the polymer crystallization. These two mechanisms could be competitive, and usually with the increase of carbon nanotube the restriction action should be the key factor during de polymer crystallization.

Table 2 - DSC result of PE and nanocomposites for different mixing processes.

\begin{tabular}{l|c|c|c}
\hline \multicolumn{1}{c|}{ Nanocomposites } & $\begin{array}{c}\text { Melt Temperature } \\
\left({ }^{\circ} \mathbf{C}\right)\end{array}$ & $\begin{array}{c}\text { Crystallization tem- } \\
\text { perature }\left({ }^{\circ} \mathbf{C}\right)\end{array}$ & $\begin{array}{c}\text { Crystallinity degree } \\
(\%)\end{array}$ \\
\hline P00S & 134 & 115 & $67 \pm 1,1$ \\
\hline
\end{tabular}




\begin{tabular}{l|c|c|c}
\hline N05S & 135 & 117 & $67 \pm 2,8$ \\
\hline N10S & 135 & 117 & $66 \pm 4,1$ \\
\hline G05S & 133 & 117 & $61 \pm 0,1$ \\
\hline G10S & 134 & 116 & 50 \\
\hline P00M & 134 & 114 & $62 \pm 6,1$ \\
\hline N05M & 135 & 119 & $70 \pm 1$ \\
\hline N10M & 136 & 119 & $68 \pm 3,1$ \\
\hline G05M & 134 & 116 & $63 \pm 7,8$ \\
\hline G10M & 134 & 117 & $55 \pm 1$ \\
\hline
\end{tabular}

Nanocomposites with graphene nanosheets have a different behavior. The samples obtained by solution present a decrease in the crystallinity degree. The G05S and G10S nanocomposites showed a reduction in the degree of crystallinity of about $9 \%$ and $25 \%$, respectively. A reduction of $12 \%$ was also observed in the nanocomposite prepared by the melting process containing $1.0 \mathrm{wt} \%$ graphene. Different behaviors can be observed in the literature. Jiang and Drzal [16] report an increase in the crystallinity degree for nanocomposites obtained by melt intercalation, and they pointed out that the nanoparticles act as a nucleation site, reducing the onset crystallization temperature. Fim et al [23] observed no significant change in the crystallinity degree in the nanocomposites with $1.2 \mathrm{wt} \%$ and $2.8 \mathrm{wt} \%$ of graphenes prepared by in situ polymerization. This behavior of crystallinity index can be related to the dispersion of the nanoparticules. At higher concentration of graphenes it is possible to have a kind of mixture of nanocomposites and microcomposites (more than $0.5 \%$ in our study). It is possible to see some experimental facts that can sustain our hypothesis in Figure 2 and figure 3 (c) and (d). Jiang and Drzal [16] observed increase in the crystallinity index in nanocomposites with maximum at $3 \%$ in volume of graphene, and then those authors found a decrease in crystallinity. They cited that this behavior could be related of a compromise between a nucleating and retarding effect of graphene on polymer crystallization. These effects can be related with the dispersion of the nanoparticles. In expholiated nanocomposites, nanoparticles exibit a strong nucleating effect and in microcomposites the nanoparticles hinders the diffusion of polymer chains to the growing crystallites. 


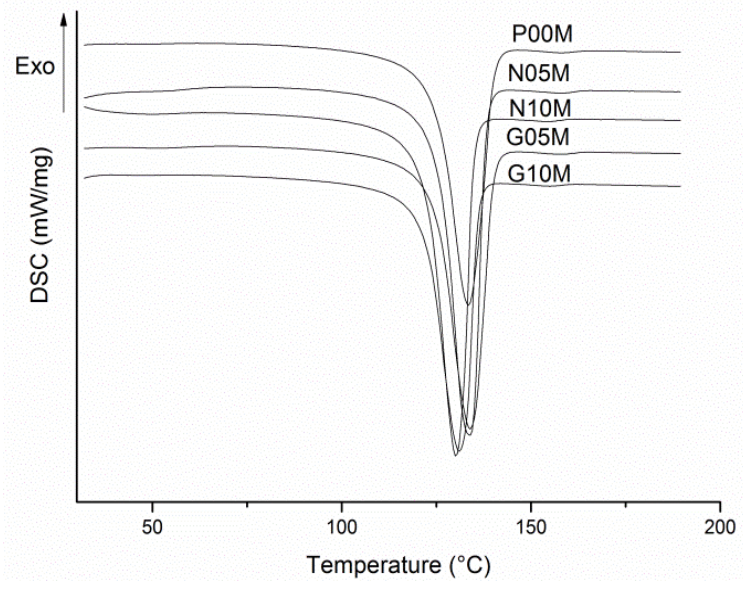

(a)

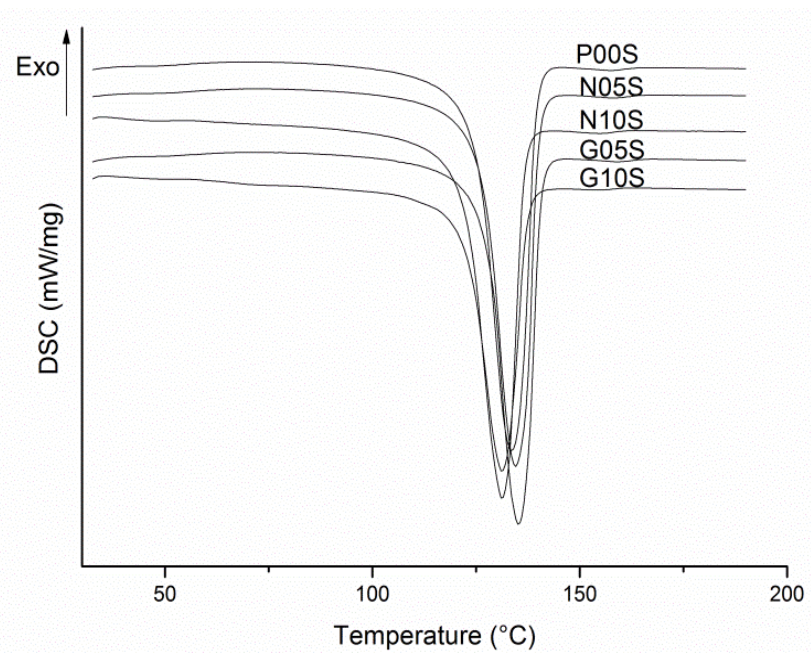

(b)

Figure 4: DSC thermograms (a) melting (b) solution methods

The data from thermogravimetric analysis (TGA) of nanocomposites for different mixing processes are summarized in Table 3. In general, the nanocomposites obtained by both methods showed no change in thermal behavior independent of the nanoparticle added. El Achaby and Qaiss [17] observed that nanocomposites with graphene in an exfoliated state showed an increase in thermal stability due to its higher interfacial area, indicating that the state of dispersion affects the thermal stability. El Achaby and Qaiss [17] using a HDPE matrix reported an increase of $24 \mathrm{oC}$ in the temperature at $5 \%$ mass loss in nanocomposites with $0,5 \%$ $\mathrm{w} / \mathrm{w}$ of graphenes and an increase of $30 \mathrm{C}$ in samples with $0,5 \% \mathrm{w} / \mathrm{w}$ of CNTs. Their results presented an trend of higher values in the beginning of mass loss for samples with graphenes than in samples with carbon nanotubes. They concluded that this is possible due to the higher surface area of graphenes when compared to carbon nanotubes. Finally, in their work the final temperature is equal for all nanocomposites. Although in this work it was found different results. It is possible to see that with $5 \%$ of mass loss samples N05S e N10S had reduction of $16 \mathrm{oC}$ and $18 \mathrm{oC}$, respectively. Also, samples G05S e G10S presented reductions of 3oC and $11 \mathrm{oC}$ at the same $5 \%$ of mass loss. In samples prepared in the melting technique it is found higher thermal stability in mass loss compared to those prepared with the same amount of nanofillers by solution method. In samples G05M and G10M it is detected and increase of 5oC and a decrease of $11 \mathrm{oC}$ respectively. Both nanofillers used in this work have high thermal conductivity, considering the number of agglomerates seen in our microscopies, this can cause thermal degradation in localized regions decreasing the thermal resistance. 
In Table 4, we see an increase in Young's modulus with increasing mass fraction of carbon nanotubes, regardless of the process used. This behavior was also observed by different authors [14, 17, 21]. Different behavior was observed with graphene addition. For the same graphene quantity, different results were obtained, indicating that the preparation method influenced the Young's modulus. Despite the reduction in the crystallinity degree of the samples obtained by solution, they have higher Young's modulus than those obtained by the melting process. As shown in transmission microscopy (Figure 3 (c) and (d)), the decrease in graphene agglomerates observed in the samples obtained by solution mixing can lead to an increase in interfacial area and consequent increase in the shear strength mechanism at the interface nanocomposites. El Achaby e Qaiss [17] observed that the addition of graphene has higher Young's modulus than the use of carbon nanotubes at concentrations of $0.5 \mathrm{wt} \%$ and $1.0 \mathrm{wt} \%$. The authors associated this behavior with the graphene higher surface area. In our case, the graphene nanocomposites did not present an intercalated or expholiated state and the nanocomposites with carbon nanotubes present a more homogeneous dispersion.

Table 3: Data obtained from TGA analysis of nanocomposites for different mixing processes

\begin{tabular}{l|c|c}
\hline \multicolumn{1}{c|}{ Nanocomposites } & $\mathbf{T}_{\text {onset }}\left({ }^{\mathbf{o}} \mathbf{C}\right)$ & $\mathbf{T}_{\text {peak }}\left({ }^{\mathbf{o}} \mathbf{C}\right)$ \\
\hline P00S & 402 & 493 \\
\hline N05S & 388 & 487 \\
\hline N10S & 395 & 490 \\
\hline G05S & 415 & 494 \\
\hline G10S & 408 & 492 \\
\hline P00M & 412 & 494 \\
\hline N05M & 400 & 492 \\
\hline N10M & 414 & 495 \\
\hline G05M & 410 & 489 \\
\hline G10M & 394 & 490 \\
\hline
\end{tabular}

It is well known in the literature that there three mechanims of reinforcement in nanocomposites: (1) Stress is transferred via a shear stress at the nanofiller/matrix interface, and the rate of load transfer depends on the shear stress. For instance, the higher the aspect ratio of nanofillers, the longer the length the carries the maximum load, and the higher the modulus of the nanocomposite.(2)A second mechanism to increase stiffness is the constraint of the polymer by nanoparticles detected by changes in the glass transition region (increases in this case), and (3) a localized yielding near the particles which is important at very low macroscopic elastic strain.

In both cases, i.e. S and M (Table 4) samples, it is possible to see the reinforcement, except in $\mathrm{M}$ samples for G05M and G10M when compared to the neat sample P00M. Very probably the increases are due to the transfer of shear stress at the nanofiller/matrix interface since employed nanoparticles have high aspect ratio, and a much higher modulus than the matrice. Unfortunately it was not possible to determine the glass transition region for our samples since our materials have high degree of crystallinity. Unfortunately in literature it was not possible to find glass transition temperatures for similar nanocomposites in the literature [26$28]$.

Comparing samples at the same content of nanoparticles from $\mathrm{S}$ and $\mathrm{M}$ it is not possible to see a different level of reinforcement. It is possible to see that for low content in S and M samples, reinforcement was higher, very probably due to a better dispersion state of nanoparticles which provided more area to stress transfer.

Concerning to nanohardness, it is possible to observe that an increase of carbon nanotube quantities leads to an increase of nanohardness for both mixing methods (Table 4). The increase of nanoparticle volume fraction may decrease the mobility of the polymer chains, and higher forces are required to cause plastic deformation. For graphene nanocomposites, a different behavior is observed. Samples with $1.0 \mathrm{wt} \%$ of graphene have lower hardness than samples with $0.5 \mathrm{wt} \%$ regardless of the process used. This behavior can be related to the fact that nanocomposites with a higher fraction of graphene have a lower crystallinity degree, and lower crystallinity organization leads to a decrease in the hardness [22]. 
BRANDENBURG, R.F.; LEPIENSKI, C.M.; BECKER, D.; COELHO, L.A.F. revista Matéria, v.22, n.4, 2017.

Table 4: Nanoindentatio results of nanocomposites prepared by solution and melt mixing process

\begin{tabular}{l|c|c}
\hline \multicolumn{1}{c|}{ Nanocomposites } & E $(\mathbf{G P a})$ & Nanohardness (GPa) \\
\hline P00S & $1.56 \pm 0.04$ & $0.051 \pm 0.002$ \\
\hline N05S & $1.74 \pm 0.03$ & $0.052 \pm 0.001$ \\
\hline N10S & $1.85 \pm 0.04$ & $0.055 \pm 0.001$ \\
\hline G05S & $1.73 \pm 0.04$ & $0.058 \pm 0.001$ \\
\hline G10S & $1.78 \pm 0.03$ & $0.057 \pm 0.001$ \\
\hline P00M & $1.64 \pm 0.03$ & $0.061 \pm 0.001$ \\
\hline N05M & $1.83 \pm 0.06$ & $0.055 \pm 0.001$ \\
\hline N10M & $1.91 \pm 0.03$ & $0.056 \pm 0.001$ \\
\hline G05M & $1.65 \pm 0.03$ & $0.054 \pm 0.001$ \\
\hline G10M & $1.65 \pm 0.02$ & $0.053 \pm 0.001$ \\
\hline
\end{tabular}

\section{CONCLUSION}

The preparation process influenced the nanocomposites morphology differently, depending on the carbon nanoparticles used. Carbon nanotubes showed better dispersion in the nanocomposites prepared by melt mixing and graphene showed smaller agglomerates in the samples prepared by solution mixing.

In the thermal properties, the type of carbon nanoparticles had a greater influence than the preparation methods. The addition of graphene led to a decrease in the crystallinity index regardless of preparation process, whereas the addition of carbon nanotubes showed no significant change regardless of the preparation process.

For mechanical properties, the preparation method and the type of carbon nanoparticles significantly affect the results obtained. Nanocomposites with carbon nanotubes exhibited variations of properties according to the particle fraction used and no significant changes with the dispersion method used were identified. Nanocomposites with graphene obtained by the solution method had the highest Young's modulus. The fraction of graphene used also affected the results, where larger fractions represented an increase of the properties.

\section{ACKNOWLEDGEMENTS}

The authors acknowledge the financial support from the FAPESC and CNPq.

\section{BIBLIOGRAPHY}

[1] HU, H., ONYEBUEKE, L., ABATAN, A. "Characterizing and Modeling Mechanical Properties of Nanocomposites- Review and Evaluation”, Journal of Minerals \& Materials Characterization \& Engineering, v. 9, n. 4, pp. 275, 2010.

[2] AJAYAN, P.M., SCHADLER, L.S,, BRAUN, P.V. Nanocomposites Science and Technology, 1. ed. Weinheim: Wiley, 2003.

[3] TANAKA, T., KOZAKO, M., FUSE, N., et al., "Proposal of a multi-core model for polymer nanocomposite dielectrics”, IEEE Transactions on Dielectrics and Electrical Insulation, v.12, n. 4, pp. 669, 2005.

[4] MAZOV, I.N., KUZNETSOV, V.L., KRASNIKOV, D.V., et al., "Structure and Properties of Multiwall Carbon Nanotubes/Polystyrene Composites Prepared via Coagulation Precipitation Technique", Journal of Nanotechnology, v. 2011, pp. 1, 2011.

[5] MITTAL, V. Polymer Nanotubes Nanocomposites - Synthesis, Properties and Applications. 1. ed. New Jersey. 2010.

[6] LEE, J-H., KIM, S.K., KIM, N.H. "Effects of the addition of multi-walled carbon nanotubes on the positive temperature coefficient characteristics of carbon-black-filled high-density polyethylene nanocomposites", Scripta Materialia, v. 55, n. 12, pp. 119, 2006.

[7] KODJIE, S.L., LI, L.Y., LI, B., et al., "Morphology and crystallization behavior of HDPE/CNT nanocomposite”, Journal Of Macromolecular Science Part B-Physics, v. 45, n. 2, pp. 231, 2006. 
[8] HE, L., XU, Q., SONG, R., et al., "Thermal and Morphological Characterization of Composites Prepared by Solution Crystallization Method of High-Density Polyethylene on Carbon Nanotubes", Polymer Composites, v. 31, n. 5, pp. 913, 2010.

[9] JEON, K., LUMATA, L., TOKUMOTO, T., et al., "Low electrical conductivity threshold and crystalline morphology of single-walled carbon nanotubes - high density polyethylene nanocomposites characterized by SEM, Raman spectroscopy and AFM", Polymer, v. 48, n. 16, pp. 4751, 2007.

[10] DU, J., ZHAO, L., ZENG, Y., et al., "Comparison of electrical properties between multi-walled carbon nanotube and graphene nanosheet/high density polyethylene composites with a segregated network structure", Carbon, v. 49, n. 4, pp.1094, 2011.

[11] SILVA, B.L., NACK, F.C., LEPIENSKI, C. M., et al., "Influence of Intercalation Methods in Properties of Clay and Carbon Nanotube and High Density Polyethylene Nanocomposites". Materials Research, v.17, n.6 ,pp. 1628, 2014.

[12] SPITALSKY, Z., TASIS, D., PAPAGELIS, K., et al., "Carbon nanotube-polymer composites: Chemistry, processing, mechanical and electrical properties", Progress in Polymer Science, v.35, n. 3, pp.357, 2010.

[13] FERRARI, A. C., MEYER, JC, SCARDACI, V., et al., "Raman Spectrum of Graphene and Graphene Layers", Physical Review Letters, v. 97, n. 18, pp. 1, 2006.

[14] CHRISSAFIS, K., PARASKEVOPOULOS, K.M., TSIAOUSSIS, I., et al., "Comparative Study of the Effect of Different Nanoparticles on the Mechanical Properties, Permeability and Thermal Degradation Mechanism of HDPE", Journal of Applied Polymer Science, v. 114, n. 3, pp. 1606, 2009.

[15] VALENTINO, O., SARNO, M., RAINONE, N.G., et al., "Influence of the polymer structure and nanotube concentration on the conductivity and rheological properties of polyethylene/CNT composites", Physical E: Low-dimensional Systems and Nanostructures, v. 40, n. 7, pp. 2440, 2008.

[16] JIANG, X., DRZAL, L.T. "Multifunctional High-Density Polyethylene Nanocomposites Produced by Incorporation of Exfoliated Graphene Nanoplatelets: Crystallization, Thermal and Electrical Properties", Polymer Composites, v.33, n. 4, pp. 636, 2012.

[17] EL ACHABY, M., QAISS, A. "Processing and properties of polyethylene reinforced by graphene nanosheets and carbon nanotubes", Materials \& Design, v. 44, pp. 81, 2013.

[18] DU, J., ZHAO, L., ZENG, Y., et al., "Comparison of electrical properties between multi-walled carbon nanotube and graphene nanosheet/high density polyethylene composites with a segregated network structure", Carbon, v. 49, n. 4, pp. 1094, 2011.

[19] SAHEBIAN, S., ZEBARJAD, S.M., VAHDATI, K. J., et al., "The effect of nano-sized calcium carbonate on thermodynamic parameters of HDPE", Journal of materials processing technology, v. 209, pp. 1310, 2009.

[20] YAN, W., PUN, C.L., SIMON, G.P. "Conditions of applying Oliver-Pharr method to the nanoindentation of particles in composites", Composites Science and Technology, v. 72, pp. 1147, 2012.

[21] VEJA, J.F., et al. "Rheology, Processing, Tensile Properties, and Crystallization of Polyethylene/Carbon Nanotube Nanocomposites", Macromolecules, v. 42, n. 13, pp. 4719, 2009.

[22] JEEVANANDA, T., et al. "Investigation of multi-walled carbon nanotube-reinforced high-density polyethylene/carbon black nanocomposites using electrical, DSC and positron lifetime spectroscopy techniques", Polymer International, v. 58, n. 7, pp. 775, 2009.

[23] FIM, F.C., GUTERRE, J.M., BASSO, N.R.S., et al.,"Polyethylene/graphite nanocomposites obtained by in situ polymerization", Journal of Polymer Science Part A: Polymer Chemistry, v. 48, n. 3, pp.692, 2010.

[24] HU, W., FRENKEL, D. "Polymer Crystallization Driven by Anisotropic Interactions", Adv Polym Sci, v.191, pp.1, 2005.

[25] PETERLIN A. "Crystallization from a strained melt or solution", Polymer Engineering and Science, v.16, n. 3, pp. 126, 1976.

[26] WEI, P., BAI, S. "Fabrication of a high-density polyethylene/graphene composite with high exfoliation and high mechanical performance via solid-state shear milling", RSC Adv., v. 5, pp. 93697, 2015.

[27] KANAGARAJ, S., VARANDA, F.R., ZHIL'TSOVA, T.V., et al.,"Mechanical properties of high density polyethylene/carbon nanotube composites", Composites Science and Technology. v. 67, n.15-16, pp.3071, 2007. 
BRANDENBURG, R.F.; LEPIENSKI, C.M.; BECKER, D.; COELHO, L.A.F. revista Matéria, v.22, n.4, 2017.

[28] KODJIE, S.L., LI, L., LI, B., et al., "Morphology and Crystallization Behavior of HDPE/CNT Nanocomposite", Journal of Macromolecular Science, Part B, v.45, pp.231, 2006. 